\title{
COMPLEX SOMATOSENSORY RECEPTIVE FIELDS OF CELLS IN THE DEEP LAMINAE OF THE HAMSTER'S SUPERIOR COLLICULUS ${ }^{1}$
}

\author{
ROBERT W. RHOADES, ${ }^{2}$ RICHARD D. MOONEY, AND MARK F. JACQUIN \\ University of Medicine and Dentistry of New Jersey, School of Osteopathic Medicine, and Rutgers Medical School, \\ Piscalaway, New Jersey 08854
}

Received September 15, 1982; Revised January 17, 1983; Accepted January 18, 1983

\begin{abstract}
Responses to separate and simultaneous application of noxious and innocuous tactile stimuli were examined for neurons recorded from the deep layers of the hamster's superior colliculus. Forty-four percent of the units isolated were responsive only to innocuous, primarily cutaneous, stimuli; $10 \%$ were activated only by noxious stimulation; and $15 \%$ were characterized as having a wide dynamic range. The remaining $31 \%$ of the somatosensory cells recorded had complex receptive field properties which have not heretofore been described for tectal neurons in any species. Ten percent of all somatosensory cells had no excitatory receptive fields, but their spontaneous discharges could be suppressed by low threshold and/or noxious stimulation of discrete portions of the body. In $18 \%$ of the units which we recorded, innocuous and noxious stimuli had opposing effects upon cellular activity. Most of these neurons had small receptive fields in which innocuous tactile stimuli yielded excitation and larger fields, often including most of the body surface, where noxious stimulation suppressed both spontaneous activity and the responses normally elicited by appropriate tactile stimulation. Finally, a very small number of units (3\% of all somatosensory cells recorded) had multiple receptive fields in which low threshold stimulation produced opposing effects on spontaneous activity. Somatosensory units were recorded in all of the deep laminae, but cells with complex response characteristics were isolated primarily in stratum griseum profundum.
\end{abstract}

The response characteristics of somatosensory superior collicular cells have been described in a number of species (Gordon, 1973; Updyke, 1974; Abrahams and Rose, 1975; Dräger and Hubel, 1975; Stein et al., 1976; Tiao and Blakemore, 1976; Chalupa and Rhoades, 1977; Albano et al., 1978; Nagata and Kruger, 1979). Virtually all of these investigators employed innocuous cutaneous or subcutaneous stimulation and have, almost without exception, reported that somatosensory collicular cells are phasically activated by such stimuli. Stein and Dixon (1978) recently showed that the deep laminae of the hamster's tectum also contain significant numbers of cells which were either exclusively responsive to noxious stimulation or which could be characterized as having a wide dynamic range (Price and Dubner, 1977). Even in

${ }^{1}$ This work was supported in part by Grants BNS8004601, EY03546, and EY04710; a Basil O'Connor Starter Research Grant from the March of Dimes National Birth Defects Foundation; the University of Medicine and Dentistry of New Jersey Foundation (R. W. R.); and National Research Service Award NS06419 (M. F. J.).

${ }^{2}$ To whom correspondence should be addressed at Department of Anatomy, UMDNJ-NJSOM and RMS, P. O. Box 55, Piscataway, NJ 08854 . this study, however, interactions between innocuous and noxious stimulation were not examined.

In the experiments reported here we have investigated the responses of collicular cells to innocuous and noxious tactile stimuli delivered either separately or simultaneously to different portions of the body surface. We have uncovered a substantial number of heretofore undescribed cells which exhibit complex interactions between these two forms of stimulation. We suggest that such neurons may be particularly important in alerting or shifting the animal's attention to potentially destructive stimuli.

Portions of this work have been presented elsewhere (Rhoades et al., 1982).

\section{Materials and Methods}

Animal preparation and recording. Successful experiments were carried out in 24 normal adult ( 3 to 8 months old) male hamsters. Animals were anesthetized with either sodium pentobarbital $(60 \mathrm{mg} / \mathrm{kg} ; 19$ hamsters) or urethane ( $1 \mathrm{gm} / \mathrm{kg}$; 5 hamsters) and prepared for recording from either the left of the right superior colliculus using methods which have been described in detail elsewhere (Rhoades, 1980, 1981a). Paralysis was induced 
with Flaxedil, and animals were artificially respired. Heart rate was monitored continuously, and body temperature was maintained at $37^{\circ} \mathrm{C}$ with a thermostatically controlled heating pad. All wound edges were infiltrated with a long-lasting local anesthetic (Nupercaine, CIBA), and paralysis and anesthesia were maintained with periodic injections of Flaxedil and the appropriate anesthetic.

Extracellular action potentials judged to be of somal origin (Hubel, 1960) were recorded using varnish-coated tungsten microelectrodes ( $\mathrm{Z}=13$ to 28 megohms, measured at $1 \mathrm{kHz}$ ). Unit activity was amplified, displayed on a storage oscilloscope from which selected traces were photographed, and played over an audiomonitor. Poststimulus time histograms and rasters of unit activity were constructed, on line, using an Ortec histogram analyzer and W.P.I. raster stepper.

Electrical stimulation. Fifty-microsecond shocks ( 0 to $3.0 \mathrm{~mA}$ ) isolated from ground were delivered to the spinal trigeminal nucleus and tract via a concentric bipolar electrode positioned at the level of the obex (this approximates the border between subnucleus interpolaris and subnucleus caudalis; Hayashi, 1980). Because most of our recordings were made in the rostral two-thirds of the colliculus, where the face and head are represented (Tiao and Blakemore, 1976; Chalupa and Rhoades, 1977; Finlay et al., 1978), shocks delivered via this electrode were usually quite effective in eliciting responses from the cells we recorded. The stimulating electrode was always positioned contralateral to the colliculus from which recordings were made. For each cell driven by trigeminal shocks, both threshold currents $(50 \%$ responses over at least 10 trials) and minimum response latencies (at twice threshold currents) were determined.

Sensory stimulation. Visual responses were tested either manually (for most cells) or using a computercontrolled movement stimulator in a manner which has been described previously (Rhoades and Chalupa, 1980; Rhoades, 1980).

Innocuous cutaneous stimuli consisted of air puffs delivered by mouth or with an airjet stimulator (Janig et al., 1977), light taps with a camel's hair brush, blunt probe, or calibrated von Frey hairs and joint rotation. Noxious stimulation was accomplished by pinching with serrated forceps. The pinch used was of sufficient intensity to be judged as painful when delivered to the back of the experimenter's hand. Thermal stimuli were not used since Stein and Dixon (1978) showed that deep layer cells responsive to heat were also activated by noxious pinch.

Experimental strategy. Most recordings were made from the rostral part of the colliculus because somatosensory receptive fields for cells in this region are smaller and their borders are more readily definable. Once a cell was isolated, its level of spontaneous activity (if any), modality, and responsivity to electrical shocks were determined. Receptive fields for visual, innocuous, and/or noxious tactile stimuli were delineated, usually by two independent observers, and the latter were plotted on large-scale standard drawings of the hamster. Following this, the effects of mechanical stimulation of other parts of the body surface (or, in the case of visual cells, all parts of the body) upon responsivity to stimuli delivered within the receptive field were tested. For wide dynamic range (WDR) cells which exhibited different receptive fields for noxious and innocuous stimulation, simultaneous application of appropriate stimuli to their respective receptive fields was also tested.

For some cells the effects of concurrent tactile stimulation upon responses to trigeminal shocks and the effects of trigeminal stimulation upon sensory evoked responses (see Rhoades, 1980) were also tested.

Histology. All electrode tracks in which data were obtained were marked with one to three electrolytic lesions $(4 \mu \mathrm{A} \times 4 \mathrm{sec}$; electrode negative). Trigeminal stimulation sites were similarly marked. At the end of the recording session the hamster was deeply anesthetized and perfused transcardially with $0.9 \%$ saline followed by $10 \%$ neutral buffered formalin. Brains were removed immediately, and blocks containing the superior colliculus and caudal medulla were postfixed for 2 to 10 days, allowed to sink in 30\% sucrose, and then cut in the transverse plane $(50-\mu \mathrm{m}$ frozen sections). Sections were stained with cresylecht violet. All data reported are from cells histologically verified as being recorded in the superior colliculus. Lesions placed at the site of trigeminal stimulation were routinely located in the dorsal trigeminal spinal tract and nucleus.

\section{Results}

The findings reported are based upon recordings from 239 collicular neurons isolated in 56 electrode penetrations. No differences were noted between the recordings carried out under urethane and sodium pentobarbital anesthesia, and the data from the two groups of hamsters have been pooled for presentation here.

Visual cells. The responses of visual cells in the hamster's superior colliculus have been detailed by a number of investigators (Tiao and Blakemore, 1976; Chalupa and Rhoades, 1977; Finlay et al., 1978; Stein and Dixon, 1979), and we shall not describe them again here. We isolated 55 exclusively visual units in stratum griseum superficiale (SGS) and stratum opticum (SO). None of these cells were activated or had their spontaneous activity or visually evoked responses enhanced or attenuated by trigeminal shocks or by either innocuous or noxious tactile stimulation.

Nineteen exclusively visual and three visual-somatosensory units were isolated in the deep laminae (those ventral to the SO). Two of the bimodal cells responded to both low threshold (LT) and noxious (Nox) stimuli and were characterized as having a wide dynamic range (see below). However, neither tactile stimuli nor trigeminal shocks altered the visual responses of any of these neurons.

Somatosensory cells. We recorded 135 cells that responded only to tactile stimulation. Five of these units were isolated in the $\mathrm{SO}$, and the rest were recorded in the deep laminae. These neurons were grouped into six types on the basis of their sensory responses.

1. LT only: Forty-four percent $(N=59)$ of the somatosensory units responded only to innocuous mechanical stimuli. Almost all $(91 \% ; N=54)$ of these cells were discharged by displacement of the hair and/or vibrissac. The rest were activated by joint movement (usually displacement of the jaw). The responses of collicular cells to innocuous tactile stimulation have already been delin- 
eated for the hamster by this (Chalupa and Rhoades, 1977; Rhoades, 1980, 1981a) and other (Tiao and Blakemore, 1976; Finlay et al., 1978; Stein and Dixon, 1978, 1979) laboratories.

LT cells were recorded with equal frequency in stratum griseum intermediale (SGI) and stratum griseum profundum (SGP) (Fig. 1). Fewer such cells were isolated in the deep fiber layers, stratum album intermedium (SAI) and stratum album profundum (SAP). Most $(85 \%, N=40)$ of the $47 \mathrm{LT}$ cells tested responded reliably to trigeminal shocks. The average latency was $8.3 \mathrm{msec}(\mathrm{SD}=3.9)$ (see Fig. 1). Of the $28 \mathrm{LT}$ cells we tested, $32 \%(N=9)$ had their sensory responses attenuated or completely suppressed by concurrent trigeminal shocks. This agrees well with findings obtained in a previous study (Rhoades, 1980) where recordings were made primarily from the posterior part of the colliculus and cervical spinal shocks were used as conditioning stimuli.

2. Nox only: Ten percent $(N=14)$ of the units we recorded were activated only by noxious stimulation. The responses of a typical Nox cell are illustrated in Figure 2. This unit was totally unresponsive to any form of LT stimulation, but a brief pinch delivered to the snout, lips, chin, or either forepaw produced a vigorous response

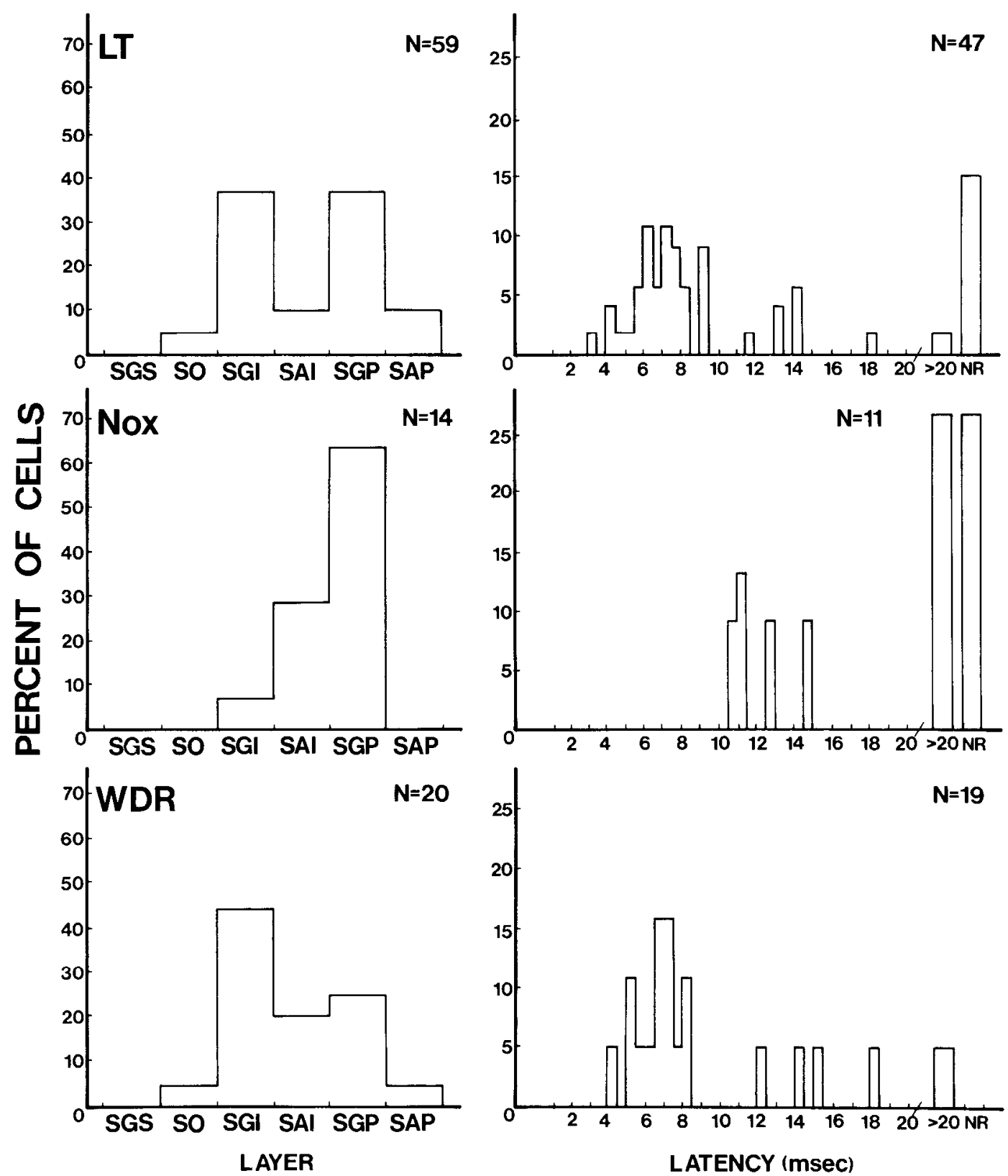

Figure 1. On the left are laminar distributions for collicular cells which responded only to low threshold stimulation $(L T)$, only to noxious stimuli $(N o x)$, or which had a wide dynamic range (WDR). Note that LT and WDR cells were fairly evenly divided between the SGI and SGP and that Nox cells were, in most cases, isolated in the SGP. The number in the upper righthand corner of each histogram indicates the number of cells in the sample. On the right are the latency distributions for responses to spinal trigeminal shocks for each group. The mean for the LT cells was $8.3 \mathrm{msec}(\mathrm{SD}=3.9)$, that for the Nox cells was 32.4 msec $(\mathrm{SD}=35.0)$, and that for the WDR cells was $10.9 \mathrm{msec}(\mathrm{SD}=12.5)$. Note that more than $25 \%$ of the Nox cells were not responsive to spinal trigeminal shocks. 

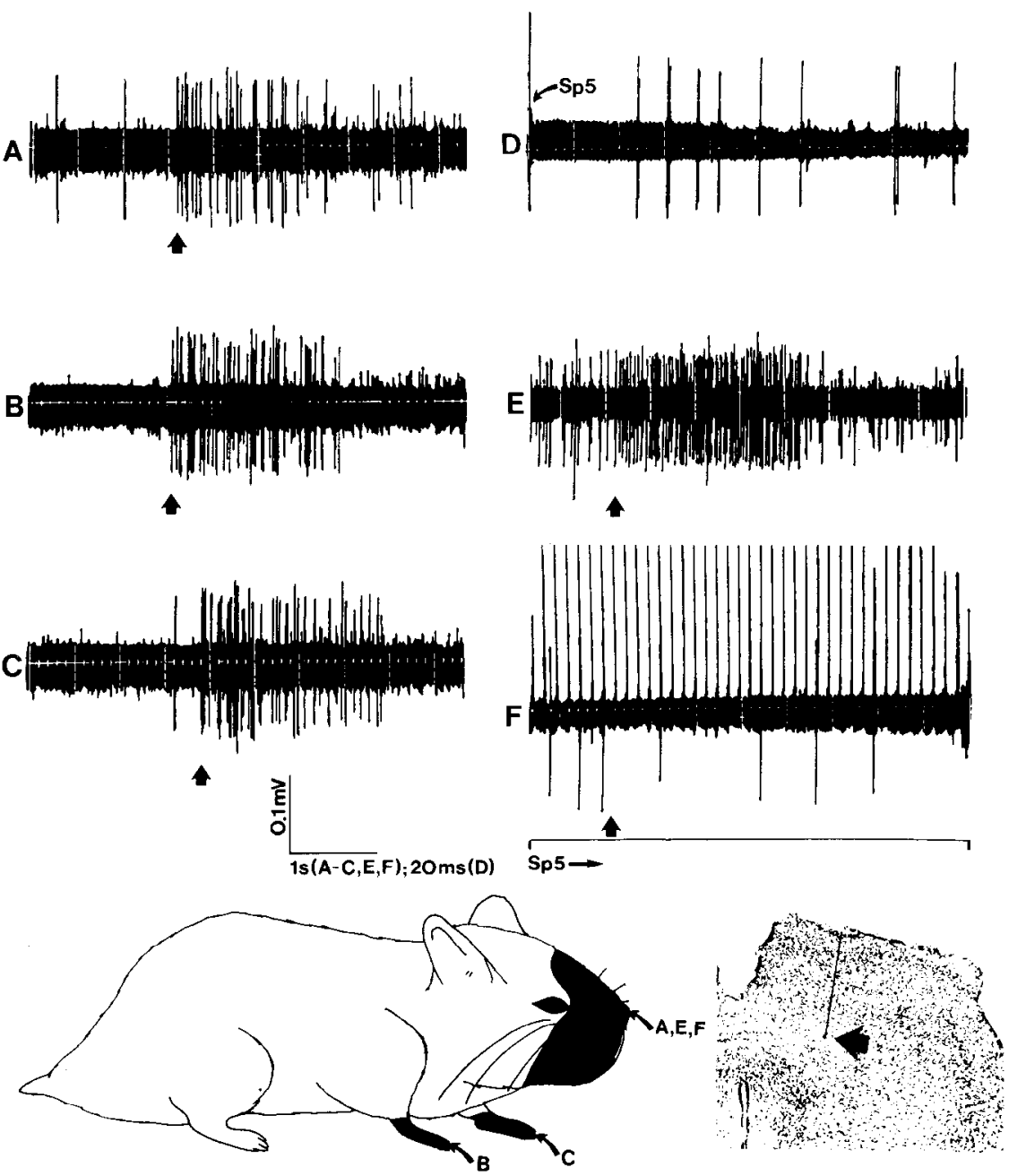

Figure 2. The response characteristics of a unit which was activated only by noxious stimuli. $A$ shows the response to a brief ( $<0.5 \mathrm{sec}$ ) pinch (onset denoted by arrow) to the nose, whereas $B$ and $C$ illustrate the discharges evoked by similar stimulation of each of the forepaws. $D$ (five overlapped traces) shows the long latency response to spinal trigeminal $(S p 5)$ shocks $(350 \mu \mathrm{A}) . E$ again shows the discharges elicited by pinching the nose, and $F$ demonstrates that a train ( 8 $\mathrm{Hz})$ of subthreshold $(125 \mu \mathrm{A}) \mathrm{Sp} 5$ shocks delivered at the same time as the pinch totally suppressed the sensory response. This cell was recorded in the SGP, at the site denoted by the arrow in the histological section. The blackened areas on the figurine are the unit's receptive fields.

which far outlasted the duration of the stimulus. The unit was only weakly activated by trigeminal shocks (Fig. $2 D$ ), but a train of electrical stimuli not sufficiently intense to activate the cell completely suppressed the unit's sensory response (Fig. $2 F$ ).

Most $(64 \%, N=9)$ Nox cells were recorded in the SGP (Fig. 1) and more than $25 \%(N=4)$ of the 11 cells tested were not responsive to trigeminal shocks. The average response latency for Nox cells $(\overrightarrow{\mathrm{X}}=32.4 \mathrm{msec}$; $\mathrm{SD}=$ $35.0)$ was also much longer than that for LT neurons. The effects of trigeminal shocks upon sensory responses were tested for seven Nox cells, and in only one instance (the unit illustrated) was clear suppression observed.

3. WDR cells: Fifteen percent $(N=20)$ of our sample of somatosensory units responded to both LT and Nox stimulation and were classified as having a wide dynamic range. The Nox responses of these cells differed from those produced by innocuous stimulation in two ways: (1) The discharge frequency produced by Nox stimuli was higher; (2) LT responses were almost always phasic, whereas those elicited by Nox stimuli were almost invariably tonic and in most cases far outlasted the duration of the stimulus. For most $(75 \%, N=15)$ WDR cells the Nox receptive field was substantially larger than the LT field. For a number $(30 \%, N=6)$ of the WDR cells the receptive fields for LT and Nox stimulation were on different parts of the body. This responsivity of different types of excitatory input from different parts of the body surface suggests that considerable convergence of different inputs. must be involved in the development of these receptive fields.

The response characteristics of a typical WDR neuron are illustrated in Figure 3. For this cell, a rapid deflection of the contralateral vibrissae produced a brief discharge 

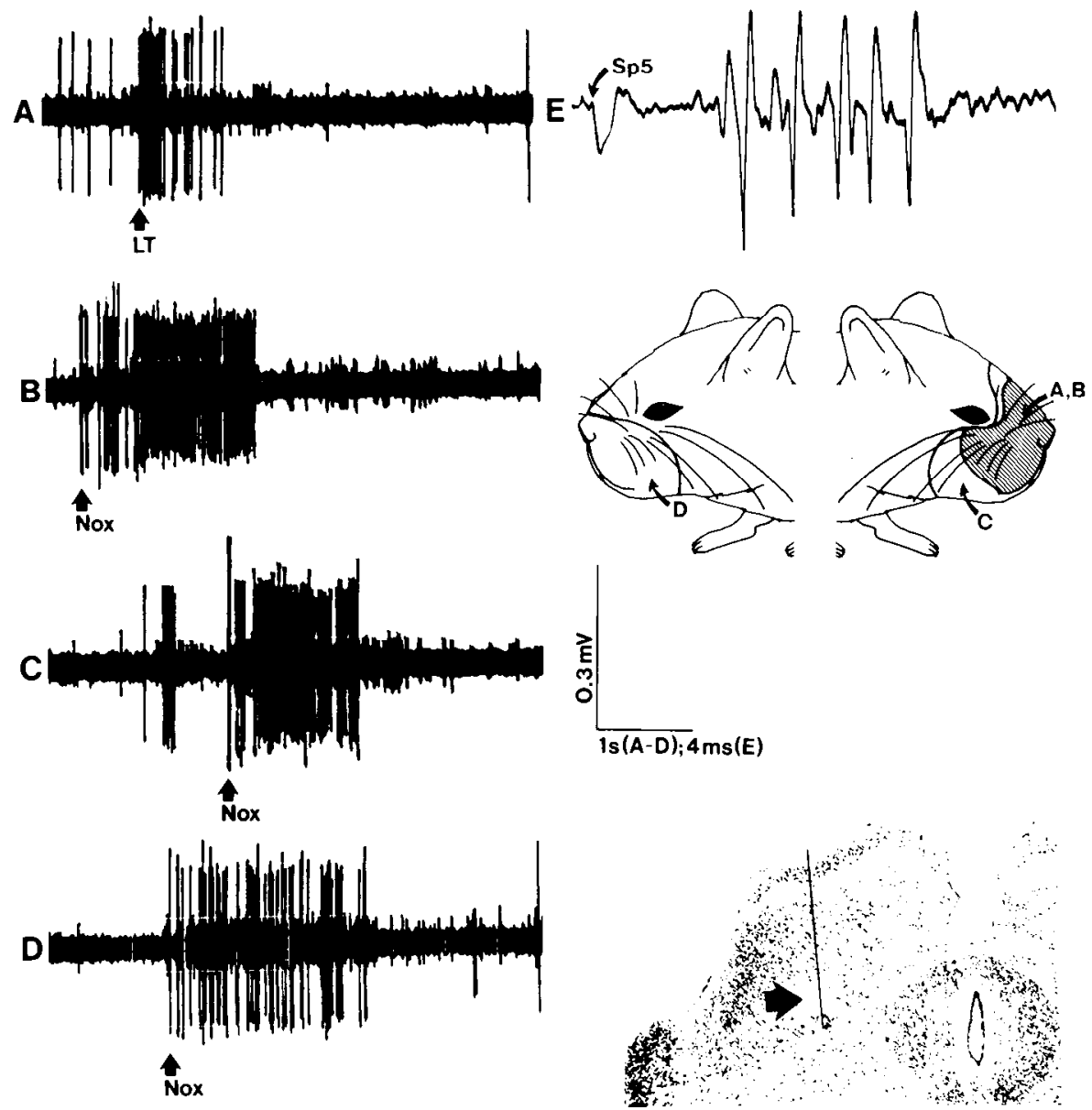

Figure 3. The responses of a WDR cell. $A$ shows the discharge evoked by a light tap with a camel's hair brush to the vibrissae (denoted by arrow). The arrow denotes stimulus onset. $B$ illustrates the effects of a pinch ( $<0.5-\mathrm{sec}$ duration) applied to this location. Deflection of the common fur or direct pressure to the whisker pad did not activate this cell. $C$ and $D$ show the responses elicited by pinches applied to other parts of the cell's receptive field, and $F$ depicts the short latency response to Sp5 shock $(45 \mu \mathrm{A})$. The shaded area on the figurine is the LT receptive field; the areas simply outlined denote the additional regions in which Nox stimuli could activate the unit. The cell was recorded in the SGP, at the lesion denoted by the arrow in the histological section.

(Fig. $3 A$ ), and a pinch delivered anywhere on either the ipsilateral (Fig. $3 D$ ) or contralateral (Fig. 3, $B$ and $C$ ) snout yielded a high frequency response which far outlasted the stimulus. This unit was activated at short latency by trigeminal shocks (Fig. $3 E$ ), and no suppressive or facilatory interactions between electrical and mechanical stimulation were noted.

WDR cells were recorded in the SO (rarely) and in all of the deep layers (Fig. 1). The laminar distribution for these cells was skewed toward the SGI; $45 \%(N=9)$ of the WDR units were isolated in this layer. All of the 19 WDR cells tested responded to trigeminal shocks and their latency distribution $(\overline{\mathrm{X}}=10.9 \mathrm{msec} ; \mathrm{SD}=12.5$ ) was similar to that for LT units (Fig. 1). The effects of trigeminal stimulation upon sensory responses were tested for only nine WDR cells. In one of these both LT and Nox responses were attenuated by trigeminal shocks, and in two others the LT but not the Nox response was suppressed.
4. Neurons which were not activated by any stimulus, but whose spontaneous activity was reduced or completely suppressed by LT and/or Nox stimulation: Ten percent $(N=14)$ of the somatosensory cells we recorded could not be discharged by any of the stimuli we employed. These cells differed from the other $(N=27 ; 11 \%$ of the total sample) unresponsive cells which we recorded in that they all had fairly high $(10$ to $50 \mathrm{~Hz})$ levels of spontaneous activity which could be reduced-usually completely suppressed - by appropriate mechanical stimulation. The receptive field characteristics of one of these cells are illustrated in Figure 4 . The spontaneous activity (Fig. $4 A$ ) of this unit was completely suppressed (Fig. $4 B$ ) by light pressure applied with a cotton swab to the nose, upper lip, or whisker pad. LT stimulation of any other part of the body (e.g., Fig. $4 D$ ) had no effect. A pinch delivered to any part of the contralateral body surface (e.g., Fig. 4, $C$ and $E$ ) or the ipsilateral forepaw also completely suppressed the unit's spontaneous dis- 

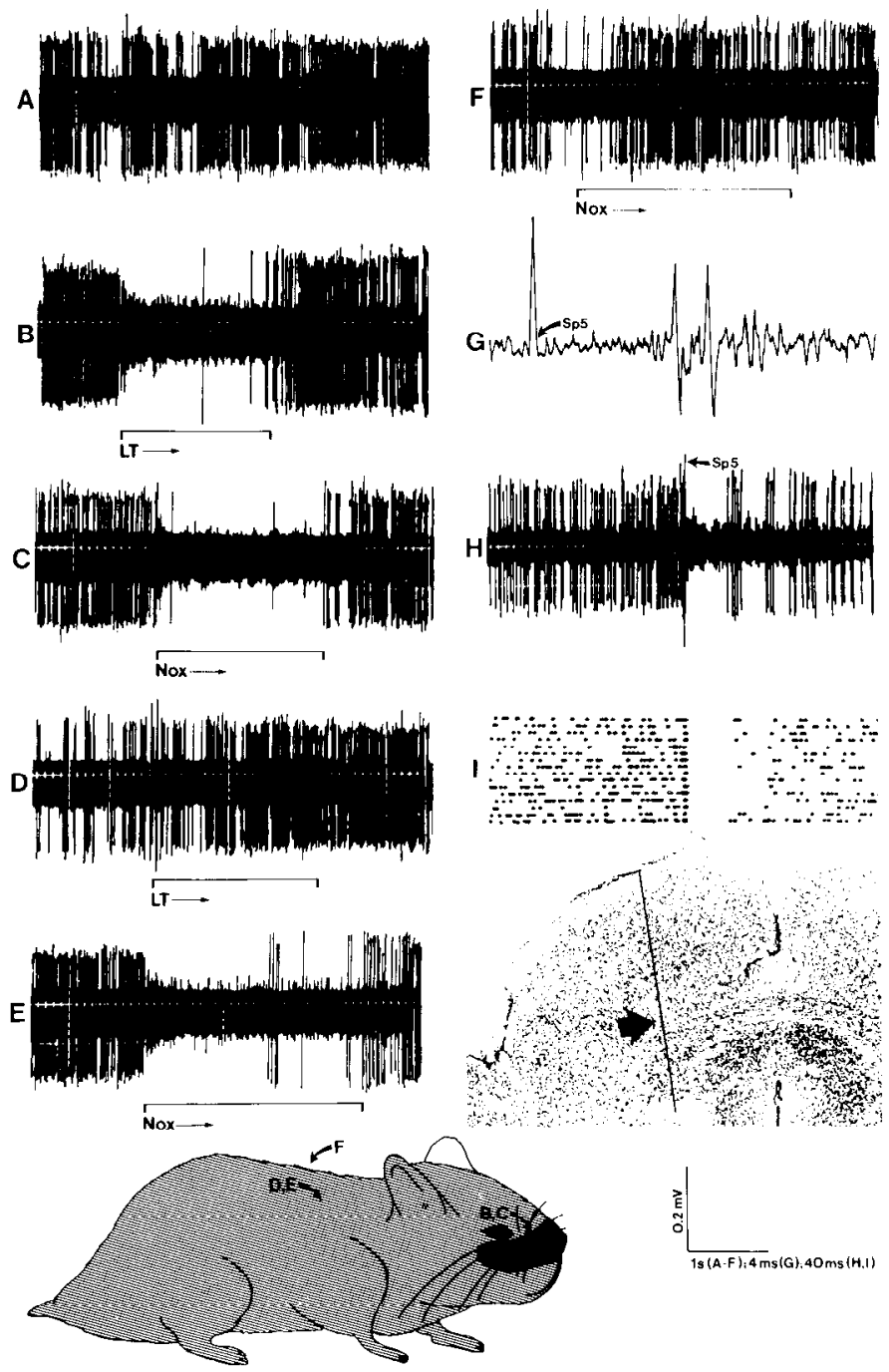

Figure 4. The responses of a unit which had its spontaneous activity suppressed by LT and Nox stimulation. $A$ shows the unit's spontaneous activity and $B$ the fact that light pressure applied to the whisker pad with a cotton swab (LT) almost completely suppressed these discharges. LT stimulation of the back $(D)$ had no effect. $C$ shows the suppressive effects of a pinch (Nox) applied to the whisker pad. Such a stimulus was also effective when applied to the contralateral $(E)$, but not the ipsilateral $(F)$, back. $G$ shows the short latency response to Sp5 shock $(145 \mu \mathrm{A})$, and the single trace in $H$ and the raster in $I$ demonstrate that this excitation was followed by $20 \mathrm{msec}$ of complete suppression and a longer period of reduced spontaneous activity. The blackened region on the figurine denotes the area where LT stimulation suppressed activity; the shaded region is the area in which Nox stimulation was effective. The unit was recorded in the SGP, at the location noted by the arrow in the histological section.

charge. This cell responded at fairly short latency to trigeminal shocks (Fig. $4 G$ ), but this activation was followed by a 20 -msec period of complete suppression and a longer (approximately 200-msec) interval of reduced spontaneous activity (Fig. $4, H$ and $I$ ).

Three of the cells in this class were affected only by LT stimulation; for five, only Nox stimuli suppressed spontaneous activity, and six were affected by either LT or Nox stimulation. Sixty-four percent $(N=9)$ of these units were recorded in the SGP, and most $(56 \% ; N=8)$ were not activated by trigeminal shocks (see Fig. 5). Nine cells did, however, exhibit suppression of spontaneous activity following trigeminal stimulation.

5. Neurons in which LT and Nox stimulation produced opposing changes in activity: Eighteen percent $(N=24)$ of the somatosensory units which we isolated had a different type of complex receptive field. Most of these units had one area on the body surface in which LT stimulation yielded excitation and another (or others) in which Nox stimuli suppressed spontaneous activity and/ or evoked discharges. The responses of one of these complex cells are illustrated in Figure 6.

During periods of low spontaneous activity (Fig. 6A) an air puff to the vibrissae (Fig. 6B) or stroking of the fur on the whisker pad or upper lip reliably activated the unit. The cell was not discharged by Nox stimulation. If, however, the scalp (Fig. 6C) or nose on the same side as the excitatory receptive field or the contralateral whisker pad was pinched during the time when the LT stimulus was delivered, the evoked discharge was suppressed. In periods of higher spontaneous activity (Fig. 6D), timelocked responses to LT stimulation were harder to detect (Fig. 6E), but Nox stimulation almost completely suppressed spontaneous discharges (Fig. 6, $G$ and $H$ ). This unit responded at short latency to trigeminal stimulation (Fig. 6, $H$ and $I$ ), but if a pinch was applied during the time when shocks were being delivered, the response to electrical stimulation was also markedly attenuated (Fig. $6 J)$.

Most $(67 \% ; N=16)$ of the cells exhibiting complex interactions between LT and Nox stimuli were of this type: they had a restricted LT receptive field in which stimulation activated the cell and a larger Nox field in which stimulation attenuated spontaneous and/or evoked activity. In many cases the Nox fields included large portions of the posterior and/or ipsilateral body surface. In 6 of the 11 cells which we tested completely Nox stimuli reduced responses to electrical as well as mechanical stimulation.

In a smaller number of units $(N=5,21 \%$ of the subsample) effects almost exactly opposing those described in the immediately preceding paragraph were observed. Data from one such cell are presented in Figure 7. This unit was not discharged by LT stimuli, but a pinch delivered anywhere on the contralateral (but not the ipsilateral) body surface produced long-lasting excitation (Fig. 7, $B$ and $C$ ). If, however, the vibrissae were rapidly displaced when a pinch was applied, the excitatory response was substantially reduced (Fig. $7 D$ ). This unit responded at short latency to trigeminal shocks (Fig. $7 E$ ), but following this response there was a 500 - to $800-$ msec period in which both sensory responses (Fig. $7 F$ ) and spontaneous activity (Fig. $7 G$ ) were suppressed.

The remaining cells in this class $(13 \%, N=3)$ had excitatory fields for both LT and Nox stimulation and additional, larger fields in which Nox stimuli suppressed evoked discharges and/or spontaneous activity.

Units with these complicated response characteristics were recorded primarily in the SGP (Fig. $5 B$ ) and they were, in most cases $(83 \% ; 19$ of 23 tested), responsive to trigeminal stimulation $(\overline{\mathrm{X}}=14.3 \mathrm{msec} ; \mathrm{SD}=25.9)$. 

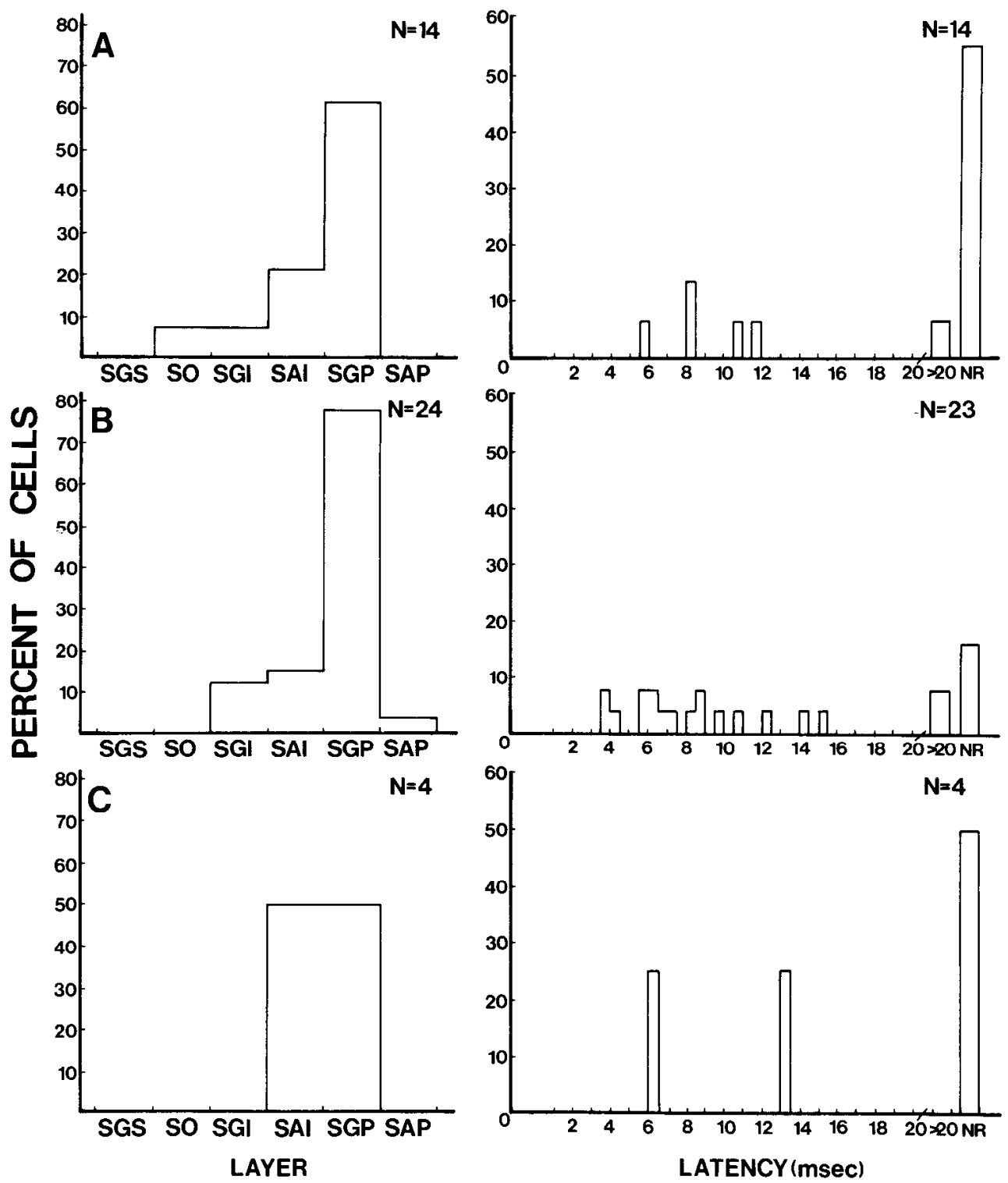

Figure 5. On the left are laminar distributions for neurons which were not activated but only suppressed by LT and/or Nox stimulation $(A)$, units where LT and Nox stimulation had opposing effects on spontaneous activity $(B)$, and cells which possessed multiple, antagonistic LT receptive fields $(C)$. Note that units in all of these classes were, in most cases, recorded in the SGP. On the right are minimum latency distributions for responses to trigeminal shocks for units in each of the three groups. The mean response latencies were $8.6 \mathrm{msec}(\mathrm{SD}=4.2)$, $14.3 \mathrm{msec}(\mathrm{SD}=25.9)$, and $9.5 \mathrm{msec}(\mathrm{SD}=4.9)$, respectively. Note that more than one-half of the units which exhibited only response suppression could not be activated by spinal trigeminal shocks. Conventions are the same as in Figure 1.

6. Cells in which LT stimulation of separate receptive fields produced opposing changes in activity: Four units ( $3 \%$ of all somatosensory units isolated) had multiple and antagonistic LT receptive fields. Data from one of these, relatively rare, units are illustrated in Figure 8 . This neuron was reliably activated by an air puff delivered to the vibrissae (Fig. $8 B$ ), but light pressure applied to the nose (in this case, with a camel's hair brush) completely suppressed the excitatory discharge. The same mechanical stimulation also increased the threshold and latency and reduced the spike number of the responses elicited by trigeminal shocks (compare Fig. $8, D$ and $E$ ).

Cells with multiple antagonistic $\mathrm{L} T$ receptive fields were recorded in the SAI and SGP (Fig. $5 C$ ), and two of the four isolated were activated by trigeminal shocks.

Collicular topography. The topography of the collicular somatosensory representation has been mapped in a variety of mammals (see the introduction and "Discussion" for citations). These maps have, in all cases, been based upon responses obtained with innocuous stimuli, and they generally (and particularly in rodents) show that the trigeminal representation encompasses the rostral one-half to two-thirds of the colliculus while the rest of the body is mapped in the caudal tectum. Our findings are consistent with these reports if one considers only activation by LT stimuli. In tracks through the rostral 

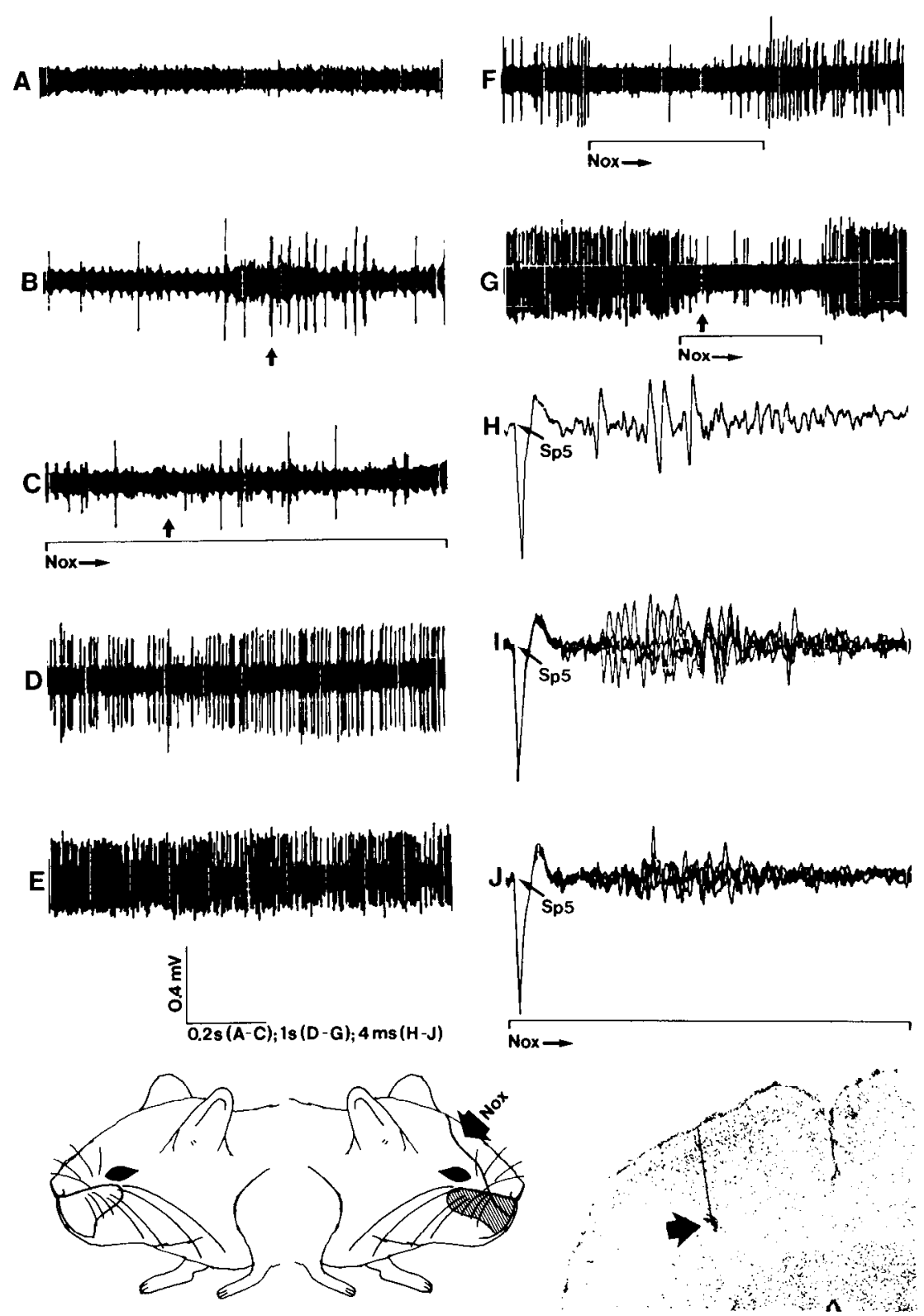

Figure 6. The responses of a cell which was excited by LT stimulation but suppressed by Nox stimuli. $A$ shows the lack of spontaneous activity during a quiescent period and $B$ the discharge elicited by an air puff (denoted by arrow) to the vibrissae. $B$ illustrates the fact that a pinch applied to the scalp before and during this same LT stimulation (arrow) totally suppressed the response. $D$ shows the cell's spontaneous discharge during a period approximately $45 \mathrm{~min}$ later than that illustrated in $A$ to $C$. Here responses to LT stimulation were harder to detect $(E)$, but Nox stimuli suppressed both this high rate of spontaneous activity ( $F$ and $G$ ) and any response to displacement of the vibrissae (arrow in $G$ ). The cell's responses to $\mathrm{Sp} 5$ shock $(210 \mu \mathrm{A})$ are shown in $H$ (single trace) and $I$ (five overlapped traces). $J$ demonstrates the almost complete suppression of this response when shocks were delivered while the scalp was being pinched. The shaded area on the righthand figurine shows the excitatory LT receptive field. The outlined areas on the two figurines denote the Nox suppressive receptive fields. The cell was recorded in the SAI at the lesion denoted by the arrow in the histological section.

colliculus cells with LT fields retricted to the contralateral face were, indeed, frequently isolated (Fig. 9A). If activation by noxious stimulation was also considered, a greater portion of the contralateral and small parts of the ipsilateral body surface was also represented in this same track (Fig. 9B). Finally, if receptive fields which produce suppression were included with those that yield activa- tion, almost the entire hamster was "mapped" in this single electrode penetration (Fig. 9C).

\section{Discussion}

Potential confounds. In this study we report changes in collicular unit responsivity which, in many cases, result 

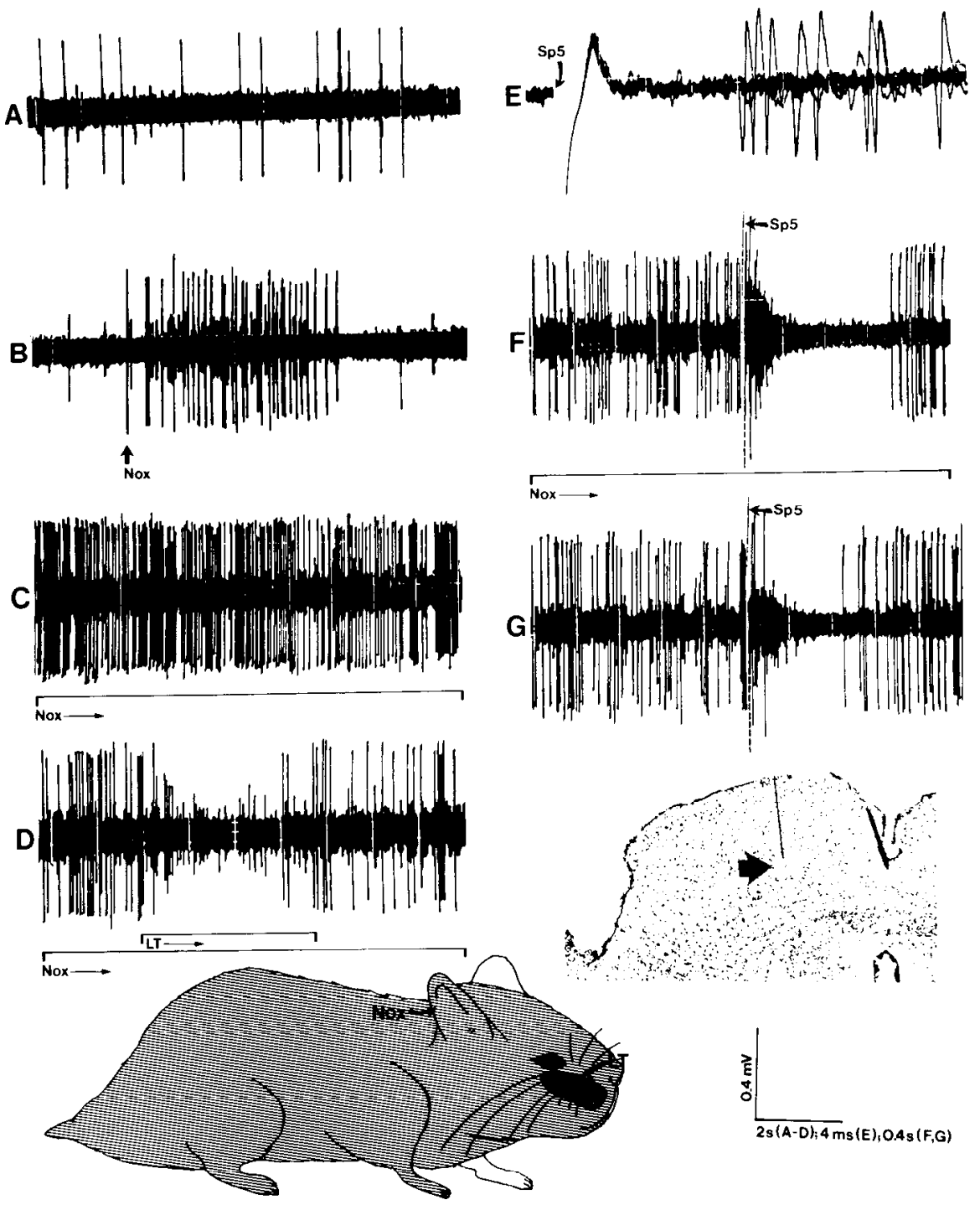

Figure 7. The responses of a unit which was excited by Nox but suppressed by LT stimulation. $A$ shows the cell's spontaneous activity and $B$ the response to a brief $(<1 \mathrm{sec})$ pinch on the ear $($ Nox, arrow). $C$ illustrates the discharges elicited by a maintained ear pinch. $D$ shows the response when the vibrissae were rapidly deflected back and forth (LT) during a portion of the time over which the pinch was applied. Note the suppression of the excitatory response. $E$ (five overlapped traces) illustrates the short latency response to Sp5 shock $(120 \mu \mathrm{A})$. F shows that Sp5 stimulation $(120 \mu \mathrm{A})$ suppressed the response to a pinch stimulus for approximately $800 \mathrm{msec}$, and $G$ (10 overlapped traces) demonstrates that Sp5 shock also reduced spontaneous activity for $500 \mathrm{msec}$. The blackened area on the figurine denotes the suppressive I T receptive field. Nox stimulation of any part of the right (but not the left) side of the hamster (shaded + blackened) excited the cell. This unit was recorded in the lower SGI, at the lesion noted by the arrow in the histological section.

from noxious stimulation. It might be argued that some or all of the effects we observed for such cells resulted from increases or decreases in blood pressure which subsequently altered brain-electrode relationships and either directly irritated or interfered with action potential production (e.g., Kuffler, 1953) by collicular cells. Although we did not monitor blood pressure, a number of observations make the above explanation of our findings extremely unlikely. First, and perhaps most importantly, we never observed any effect of noxious stimulation upon the responses of exclusively visual cells in the superficial layers. If changes in responsivity induced by noxious stimulation were conveyed by a "non-neural" route, it seems likely that these effects should be seen for superficial layer visual cells as well as for deep layer somatosensory cells.

Second, not all deep layer somatosensory cells were affected by noxious stimulation; $47 \%$ of all the somatosensory units tested were responsive only to innocuous tactile stimulation. We should note further that the lam- 

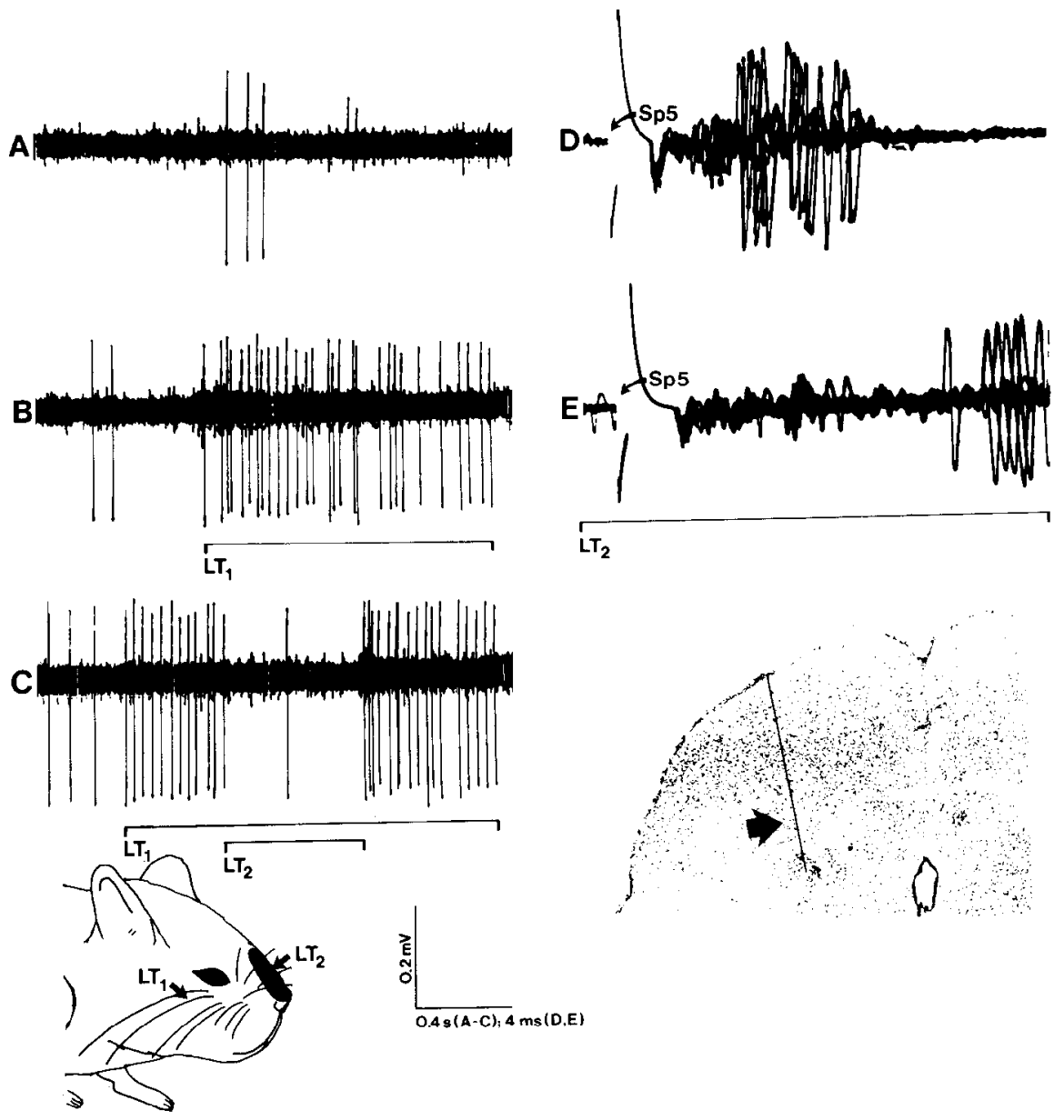

Figure 8 . The responses of a cell with antagonistic LT receptive fields. $A$ shows the cell's spontancous activity and $B$ the response elicited by an airstream $\left(L T_{l}\right)$ delivered to the vibrissae. $C$ demonstrates that when light pressure was applied with a camel's hair brush to the region just above the nose $\left(L T_{2}\right.$, the blackened area on the figurine) the excitatory response elicited by $\mathrm{LI}_{1}$ was suppressed. $D$ (five overlapped traces) shows the response of the cell to $\operatorname{Sp5}$ shock $(175 \mu \mathrm{A}$ ), and $E$ (five overlapped traces) illustrates the fact that application of $\mathrm{LT}_{2}$ increased the response latency to $\mathrm{Sp} 5$ shock $(500 \mu \mathrm{A})$ by approximately $100 \%$. This unit was recorded in the $\mathrm{SGP}$, at the point noted by the arrow in the histological section.

inar distribution of units whose responses were affected by noxious stimulation, especially those which exhibited response suppression, was significantly different from that for units which responded only to innocuous stimuli.

Finally, the receptive fields from which effects of noxious stimulations could be obtained, although large in some instances, were also quite restricted for other units (e.g., Figs. 2, 3, and 5). Even the larger fields were, in a number of cases, sharply delimited by the midline of the body surface (e.g., Figs. 4 and 7). Such receptive field limitations are clearly inconsistent with the argument that the responses observed were mediated by blood pressure changes.

Relation to previous studies. As noted in the introduction, most previous experiments concerned with somatosensory superior collicular neurons employed only innocuous tactile stimuli and thus produced results quite different from those reported here. Tiao and Blakemore (1976) and Chalupa and Rhoades (1977) did note the existence of several deep layer cells in hamster whose spontaneous activity was reduced by innocuous cutaneous stimulation, but the receptive field properties of these cells were not described in detail. Some aspects of our data can be compared with those of Stein and Dixon (1978). They reported much higher percentages of WDR and Nox cells than were recorded in this study. Over onehalf of their somatosensory units were classified as having a wide dynamic range, and $35 \%$ were specifically nociceptive. Only $10 \%$ of the somatosensory cells we isolated responded exclusively to noxious stimuli, and an additional $15 \%$ were classified as WDR. Some of the difference between these two sets of results can certainly be attributed to the fact that a number of the cells we classified as complex would have been included in the WDR or Nox groups if responses to simultaneous application of noxious and innocuous stimuli had not been tested. Furthermore, Stein and Dixon (1978) included units isolated in the tegmentum and periaqueductal gray in their data set, whereas all the cells we report were recorded in the colliculus. A point of strong agreement 


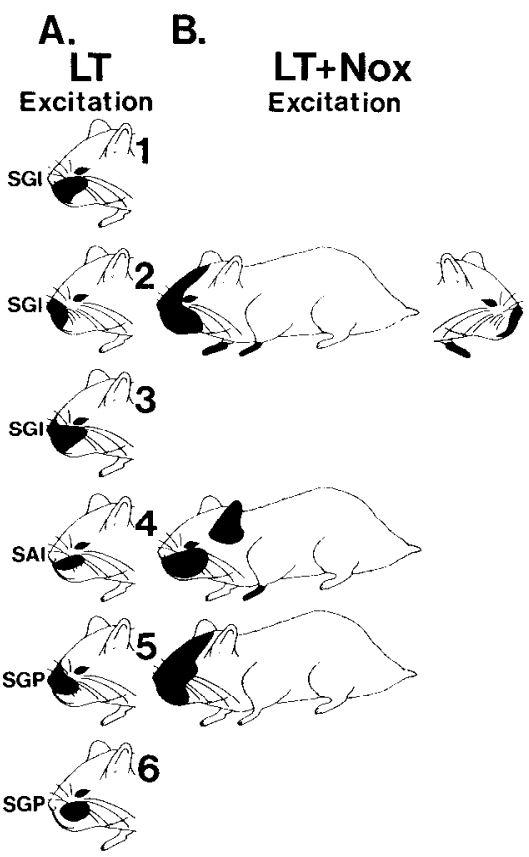
C. LT+Nox
Excitation or Suppression
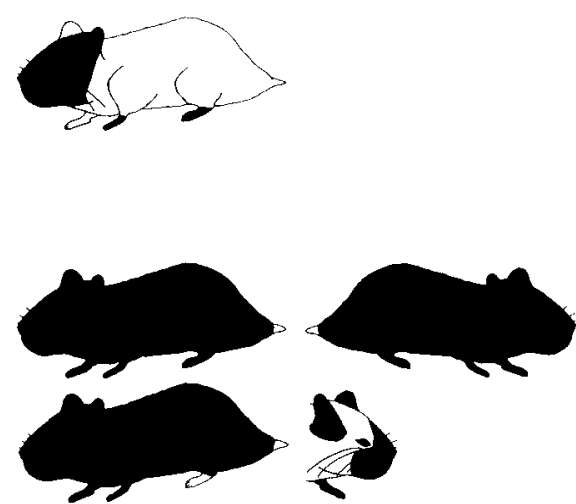

Figure 9. Receptive fields (blackened areas on figurines) for six cells somatosensorily recorded in a single penetration. The lamina in which each cell was isolated is noted along the lefthand edge of the figure. In the left column receptive fields for LT excitation are plotted. In the center column Nox receptive fields for cells $(2,4$, and 5 ) which were activated by such stimuli have been added. In the right column fields from which suppression could be obtained have been darkened, along with those which yielded excitation (cells 3, 5, and 6).

between our results and those of Stein and Dixon (1978) is that most Nox cells in both studies were recorded in the ventral part of the deep layers (primarily the SGP).

Sources of input to collicular somatosensory cells. It is well known (see Edwards, 1980, for a review) that there are a large number of potential somatosensory afferents to the deep tectal laminae, and it should be obvious that any number of these might be involved in the synthesis of the different types of somatosensory receptive fields we recorded. A related but somewhat different question is whether the complicated collicular receptive fields can be completely accounted for by the response characteristics of neurons in structures which innervate the tectum.

The rostral portion of the deep laminae receives a substantial input from the brainstem trigeminal nuclear complex (Stewart and King, 1963; Edwards et al., 1979; Huerta et al., 1981; Killackey and Erzurumlu, 1981; Rhoades, 1981a), and some aspects of the complex interactions we have observed between LT and Nox stimulation in the colliculus have also been reported for brainstem trigeminal neurons. Khayyat et al. (1975), Sessle and Greenwood (1976), and Sessle et al. (1981) have all noted suppressive interactions between LT and Nox stimulation in such cells, and the LT and Nox receptive fields for these units were often quite disparate. Unlike the case in the colliculus, however, cells exhibiting such interactions could be activated by both LT and Nox stimuli. The fact that peripheral stimuli suppressed responses to trigeminal shocks for a number of collicular cells having complex somatosensory receptive fields also suggests that the complicated receptive fields we observed were not synthesized in the brainstem trigeminal complex and transmitted "wholesale" to the colliculus.
Another possible source of the complex receptive fields in the deep tectal laminae is the projection from the somatosensory cortex (Wise and Jones, 1977; Killackey and Erzurumlu, 1981; Rhoades, 1981a; Rhoades et al., 1981). Lund and Sessle (1974) have, indeed, recorded cells in the presylvian, anterior orbital, anterior coronal, and anterior lateral sigmoid gyri of the cat which received widely divergent input and which exhibited suppressive interactions between LT and Nox stimulation. Like the cells in the trigeminal nuclear complex, however, these units were all activated by both LT and Nox stimuli. Neurons with similar response characteristics have also been recorded in SII of the cat by Carreras and Anderson (1963).

The spinal input to the colliculus, both from the dorsal horn and the lateral cervical nucleus (Edwards et al., 1979; Rhoades, 1981a) might also be involved in organizing complex somatosensory collicular receptive fields. Le Bars et al. (1979) have shown that some dorsal horn cells exhibit "diffuse noxious inhibitory controls." These investigators found that the responses of virtually all WDR cells in the dorsal horn of the rat spinal cord could be suppressed by noxious stimuli delivered to much of the body surface, including the face. It is known that some spinotectal cells in hamster have a wide dynamic range (Rhoades, 1981b), and it is thus reasonable to expect that they might also exhibit such diffuse suppressive influences. Many neurons in the lateral cervical nucleus of the rat can be excited by noxious stimuli delivered over most of the body (not including the head) (Geisler et al., 1979), and it may be that inpul from these cells is important in the organization of collicular responses. However, both of these pathways terminate only in the caudal one-half of the tectum (Antonetty and Webster, 
1975; Rhoades et al., 1981), and intracollicular circuits must be involved if these afferents contribute to the receptive fields of units in the rostral part of this nucleus.

Units responsive to somatosensory stimulation have also been recorded in substantia nigra, pars reticulata (Barasi, 1978; Harper et al., 1979), zona incerta (Kruger and Albe-Fessard, 1960; Erickson et al., 1964; Pubols and Pubols, 1966), locus ceruleus (Korf et al., 1974; Guyenet, 1980; Akaike, 1982), raphe nuclei (e.g., Nakahama, et al., 1981), and external nucleus of the inferior colliculus (Aitkin et al., 1981), but interactions between LT and Nox stimuli have not, to our knowledge, been investigated. This brief review thus supports, although by no means conclusively, the argument that neurons in a number of structures that innervate the deep layers have response characteristics which make them likely contributors to the complex somatosensory fields we have described. None of those inputs, however, seems to be able to account completely for the collicular receptive fields.

Implications for collicular organization. Regardless of whether they are synthesized in the colliculus, the receptive field characteristics of some of the deep layer neurons we recorded seem ideally suited to the orienting or attentional functions which have been ascribed to this structure (see Ingle and Sprague, 1975, for a review). It has been well documented that neuronal activity in the deep laminae is tightly correlated with directed movements of the eyes and head (see Sparks and Pollack, 1977; and Wurtz and Albano, 1980, for reviews), ears (Stein and Clamann, 1981), and even the vibrissae (Stein, 1981). Stein (1981) has noted that, "stimulation-evoked movements seemed to result in the orientation of many receptor organs toward the site of a presumptive natural stimulus (which would have activated this area of the colliculus via afferent pathways)." In the normal course of events, numerous, probably in most cases innocuous, tactile stimuli are impinging upon the animal's body surface at any given moment, and each of these presumably creates a focus of activity in the topographically appropriate portion of the deep laminae. If the output of the colliculus depends upon some "average" (see Sparks and Mays, 1980; McIlwain, 1982) of this topographically distributed activity, one could argue that, at any given moment, a particular locus in the tectum may have only a slight advantage over other loci in determining the motor response ultimately produced by multiple peripheral stimuli.

An important issue thus becomes the manner in which attention is differentially shifted toward and maintained on behaviorally significant peripheral inputs. Wurtz and his colleagues (e.g., Wurtz and Mohler, 1976) have made considerable strides in answering this question for visually evoked saccadic activity. If one assumes that noxious inputs are behaviorally more important than innocuous stimuli, then the responses of some of the cells we have recorded may provide a clue to the way in which the tectum solves this problem for tactile sensory information. Responses to noxious stimuli in the deep layers differ from those to LT stimulation in two important ways. First, they are tonic and in many cases last considerably longer than the stimulus (Stein and Dixon, 1978; present study). Second, the response to noxious input often includes suppression of spontaneous and evoked activity in parts of the tectum at a considerable distance away from the representation of the point of stimulation. Thus the pattern of activity in the deep layers would be focused to a much greater extent by a noxious stimulus than by innocuous input, and this focus would last for at least as long as that stimulus was applied. This proposal must be tempered somewhat by the fact that many excitatory receptive fields for noxious stimulation were quite large and in some cases discontinuous (see also Stein and Dixon, 1978). However, the portion of the body surface from which noxious stimulation elicited excitation was, for at least some cells (e.g., Figs. 3 and 6), fairly restricted, and it does seem reasonable to argue that these receptive fields might allow at least crude localization of noxious input.

Our results have one other implication for collicular organization. The difference in the laminar distributions for the different somatosensory cell types we have recorded indicates that very different aspects of tactile information processing may occur in different deep laminae. In particular, neurons with complex receptive fields were, in most cases, isolated in the SGP. This suggests that it may not be correct to consider the deep laminae as a unitary structure or to simply include these layers with the "reticular core" (Edwards, 1980).

\section{References}

Abrahams, V. C., and P. K. Rose (1975) Projections of extraocular, neck muscle, and retinal afferents to superior colliculus in the cat: Their connections to cells of origin of tectospinal tract. J. Neurophysiol. 38: 10-18.

Aitkin, L. M., C. E. Kenyon, and P. Philpott (1981) The representation of the auditory and somatosensory systems in the external nucleus of the cat inferior colliculus. J. Comp. Neurol. 196: 25-40.

Akaike, T. (1982) Periodic bursting activities of locus coeruleus neurons in rat. Brain Res. 239: 629-633.

Albano, J. F., A. T. Humphrey, and T. T. Norton (1978) Laminar organization of receptive-field properties in tree shrew superior colliculus. J. Neurophysiol. 41: 1140-1164.

Antonetty, C. M., and K. E. Webster (1975) The organization of the spinotectal projection. An experimental study in the rat. J. Comp. Neurol. 163: 449-466.

Barasi, S. (1978) Effect of noxious stimulation on a population of substantia nigra neurones. J. Physiol. (Lond.) 284: 85p$86 p$.

Carreras, M., and S. A. Anderson (1963) Functional properties of neurons of the anterior ectosylvian gyrus of the cat. J. Neurophysiol. 26: 100-126.

Chalupa, L. M., and R. W. Rhoades (1977) Responses of visual, somatosensory, and auditory neurones in the golden hamster's superior colliculus. J. Physiol. (Lond.) 270: 595-626.

Dräger, U. C., and D. H. Hubel (1975) Responses to visual stimulation and relationship between visual, auditory and somatosensory inputs in mouse superior colliculus. J. Neurophysiol. 38: $690-713$.

Edwards, S. B. (1980) The deep cell layers of the superior colliculus: Their reticular characteristics and structural organization. In The Reticular Formation Revisited, J. A. Hobson and M. A. B. Brazier, eds., pp. 193-209, Raven Press, New York.

Edwards, S. B., C. L. Ginsburgh, C. K. Henkel, and B. E. Stein (1979) Sources of subcortical projections to the superior colliculus in the cat. J. Neurophysiol. 184: 309-330.

Erikson, R. P., J. A. Jane, R. Waite, and I. T. Diamond (1964) Single neuron investigation of sensory thalamus of the opossum. J. Neurophysiol. 27: 1026-1047. 
Finlay, B. L., S. E. Schneps, K. G. Wilson, and G. E. Schneider (1978) Topography of visual and somatosensory projections to the superior colliculus of the golden hamster. Brain Res. 142: 223-235.

Geisler, G. J., Jr., G. Urca, T. Cannon, and J. C. Liebeskind (1979) Response properties of neurons of the lateral cervical nucleus in the rat. J. Comp. Neurol. 186: 65-78.

Gordon, B. (1973) Receptive fields in deep layers of cat superior colliculus. J. Neurophysiol. 36: 157-178.

Guyenet, P. G. (1980) The coeruleospinal noradrenergic neurons: Anatomical and electrophysical studies in the rat. Brain Res. 189: 121-133.

Harper, J. A., T. Labuszewski, and T. I. Lidsky (1979) Substantia nigra unit responses to trigeminal sensory stimulation. Exp. Neurol. 65: 462-470.

Hayashi, H. (1980) Distributions of vibrissae afferent fiber collaterals in the trigeminal nuclei as revealed by intra-axonal injection of horseradish peroxidase. Brain Res. 183: 442-446.

Hubel, D. H. (1960) Single unit activity in lateral geniculate body and optic tract of unrestrained cats. J. Physiol. (Lond.) 150: 91-1-4.

Huerta, M. F., A. J. Frankfurter, and J. K. Harting (1981) The trigeminocollicular projection in the cat: Patch-like endings within the intermediate gray. Brain Res. 211: 1-13.

Ingle, D., and J. M. Sprague (1975) Sensorimotor function of the midbrain tectum. Neurosci. Res. Program Bull. 13: 169287.

Janig, W., T. Schoultz, and W. A. Spencer (1977) Temporal and spatial parameters of excitation and afferent inhibition in cuneothalamic relay neurons. J. Neurophysiol. 40: 822-835.

Khayyat, G. F., Y. J. Yu, and R. B. King (1975) Response patterns to noxious and non-noxious stimuli in rostral trigeminal relay nuclei. Brain Res. 97: 47-60.

Killackey, H. P., and R. S. Erzurumlu (1981) Trigeminal projections to the colliculus of the rat. J. Comp. Neurol. 201: 221-242.

Korf, J., B. S. Bunney, and G. K. Aghajanian (1974) Noradrenergic neurons: Morphine inhibition of spontaneous activity. Eur. J. Pharmacol. 25: 165-169.

Kruger, I., and D. Albe-Fessard (1960) Distribution of responses to somatic efferent stimuli in the diencephalon of the cat under chloralose anesthesia. Exp. Neurol. 2: 442-467.

Kuffler, S. W. (1953) Discharge patterns and functional organization of mammalian retina. J. Neurophysiol. 16: 37-68.

Le Bars, D., A. H. Dickenson, and J -M. Besson (1979) Diffuse noxious inhibitory controls (DNIC). I. Effects on dorsal horn convergent neurones in the rat. Pain 6: 283-304.

Lund, J. P., and B. J. Sessle (1974) Oral-facial and jaw muscle afferent projections to neurons in cat frontal cortex. Exp. Neurol. 45: 314-331.

McIlwain, J. T. (1982) Lateral spread of neural excitation during microstimulation in intermediate gray layer of cat's superior colliculus. J. Neurophysiol. 47: 167-178.

Nagata, T., and L. Kruger (1979) Tactile neurons of the superior colliculus of the cat: Input and physiological properties. Brain Res. 174: 19-37.

Nakahama, H., K. Shima, M. Yamamoto, and K. Aya (1981) Regularity of the spontaneous discharge of neurons in the nucleus raphe dorsalis of the cat. Neurosci. Lett. 23: 151-166.

Price, D. D., and R. Dubner (1977) Neurons that subserve the sensory-discriminatory aspects of pain. Pain 3: 307-338.

Pubols, B. H., and L. M. Pubols (1966) Somatic sensory representation in the thalamic ventrobasal complex of the Virginia opossum. J. Comp. Neurol. 127: 19-34.

Rhoades, R. W. (1980) Response suppression induced by afferent stimulation in the superficial and deep layers of the hamster's superior colliculus. Exp. Brain Res. 40: 185-195.
Rhoades, R. W. (1981a) Cortical and spinal somatosensory input to the superior colliculus in the golden hamster: An anatomical and electrophysiological study. J. Comp. Neurol. 195: 415-432.

Rhoades, R. W. (1981b) Organization of somatosensory input to the deep collicular laminae in hamster. Behav. Brain Res. 3: 201-222.

Rhoades, R. W., and L. M. Chalupa (1980) Effects of neonatal enucleation on receptive-field properties of visual neurons in superior colliculus of the golden hamster. J. Neurophysiol. 43: 595-611.

Rhoades, R. W., D. R. DellaCroce, and I. Meadows (1981) Reorganization of somatosensory input to superior colliculus in neonatally enucleated hamsters: Anatomical and electrophysiological experiments. J. Neurophysiol. 46: 855-877.

Rhoades, R. W., M. Jacquin, and R. Mooney (1982) Complex somatosensory receptive fields in the deep layers of the hamster's superior colliculus. Soc. Neurosci. Abstr. 8: 1026.

Sessle, B. J., and L. F. Greenwood (1976) Inputs to trigeminal brain stem neurones from facial, oral, tooth pulp and pharyngolaryngeal tissues. I. Responses to innocuous and noxious stimuli. Brain Res. 117: 211-226.

Sessle, B. J., J. W. Hu, R. Dubner, and G. E. Lucier (1981) Functional properties of neurons in cat trigeminal subnucleus caudalis (medullary dorsal horn). II. Modulation of responses to noxious and nonnoxious stimuli by periaqueductal gray, nucleus raphe magnus, cerebral cortex, and afferent influences and effect of naloxone. J. Neurophysiol. 45: 193-207.

Sparks, D. L., and L. E. Mays (1980) Movement fields of saccade-related burst neurons in the monkey superior colliculus. Brain Res. 190: 39-50.

Sparks, D. L., and J. G. Pollack (1977) The neurol control of saccadic eye movements: The role of the superior colliculus. In Eye Movements, B. A. Brooks and F. J. Bajandas, eds., Plenum Publishing Corp., New York.

Stein, B. E. (1981) Organization of the rodent superior colliculus: Some comparisons with other mammals. Behav. Brain Res. 3: 175-188.

Stein, B. E., and H. P. Clamann (1981) Control of pinna movements and sensorimotor register in cat superior colliculus. Brain Behav. Evol. 19: 180-192.

Stein, B. E., and J. Dixon (1978) Superior colliculus cells respond to noxious stimuli. Brain Res. 158: 65-73.

Stein, B. E., and J. Dixon (1979) Properties of superior colliculus neurons in the golden hamster. J. Comp. Neurol. 183: 269284.

Stein, B. E., B. Magalhaes-Castro, and L. Kruger (1976) Relationship between visual and tactile representations in cat superior colliculus. J. Neurophysiol. 39: 401-419.

Stewart, W. A., and R. B. King (1963) Fiber projections from the nucleus caudalis of the spinal trigeminal nucleus. J. Comp. Neurol. 121: 271-295.

Tiao, Y. -C., and C. Blakemore (1976) Functional organization in the superior colliculus of the golden hamster. J. Comp. Neurol. 168: 483-504.

Updyke, B. V. (1974) Characteristics of unit response in superior colliculus of the cebus monkey. J. Neurophysiol. 37: 896-909.

Wise, S. P., and E. G. Jones (1977) Somatotopic and columnar organization in the corticotectal projection of the rat somatic sensory cortex. Brain Res. 133: 223-235.

Wurtz, R. H., and J. E. Albano (1980) Visual-motor function of the primate superior colliculus. Annu. Rev. Neurosci. 3: 189226.

Wurtz, R. H., and C. W. Mohler (1976) Enhancement of visual responses in monkey striate cortex and frontal eye fields. J. Neurophysiol. 39: 766-772. 